\title{
Estimasi Biaya Pengembangan Aplikasi Pemantauan Tagihan Menggunakan Metode Function Points
}

\author{
Desinta Ayudia Wanda Putri, Intan Tika Hartiningrum, Renny Sari Dewi * \\ Fakultas Teknologi Informasi dan Kreatif, Sistem Informasi, Universitas Internasional Semen Indonesia, Gresik, Indonesia \\ Email: ${ }^{1}$ desintaayudiawandaputri@gmail.com, ${ }^{2}$ tikaintan97@gmail.com, ${ }^{3,{ }^{*}}$ renny.dewi@uisi.ac.id \\ Email Penulis Korespondensi renny.dewi@uisi.ac.id
}

Submitted 15-01-2020; Accepted 29-01-2020; Published 15-02-2020

\begin{abstract}
Abstrak
Sebuah proyek estimasi perangkat lunak Enterprise Resource Planning (ERP) dilakukan agar pengalokasian dana yang dimiliki tidak mengakibatkan underestimate atau over-estimate. Under-estimate terjadi karena kurangnya pengalokasian sumber daya sehingga dapat berpotensi kegagalan proyek sedangkan Over-estimate terjadi karena pengalokasian sumber daya yang berlebihan. Analisis perkiraan biaya nantinya akan didasarkan pada penghitungan Function Point, Penelitian menjelaskan pembagian lingkup kerja perangkat lunak Monitoring Tagihan (MONITA) pada perusahaan PT XYZ. Tahap penelitihan dimulai dengan tahap studi literatur, analisis tahapan metode Fuction Points memuat kuesioner, wawancara ke stakeholder, analisis data, perhitungan, dan konversi effort estimasi biaya. Pada perhitungan matematika pada perangkat lunak Monitoring Tagihan (MONITA) menghasilkan estimasi effort sejumlah 1.792,66 orang/jam dan total biaya sebesar 90.457.909. Analisis perbandingan antara metode Function Point pada perangkat lunak Monitoring Tagihan (MONITA) dapat menjadi bahan pertimbangan PT XYZ dalam menyelesaikan masalah untuk memperkembangkan perangkat lunak.
\end{abstract}

Kata Kunci: Estimasi Biaya, Metode Function Point, dan PT XYZ.

\begin{abstract}
An Enterprise Resource Planning (ERP) software estimation project is carried out so that the allocation of funds owned does not result in underestimation or over-estimation. Under-estimation occurs because of the lack of allocation of resources so that it can potentially lead to project failure while Over-estimation occurs because of the allocation of excessive resources. Cost estimation analysis will be based on the calculation of Function Points. The study explains the division of work scope of the Bill Monitoring software (MONITA) at the company PT XYZ. The research stage starts with the study of literature, analysis of the stages of the Fuction Points method containing questionnaires, interviews with stakeholders, data analysis, calculations, and conversion of cost estimation efforts. In mathematical calculations on the Bill Monitoring software (MONITA) produces an estimated effort of 1,792.66 people / hour and a total cost of 90,457,909. Comparative analysis between the Function Point method in Bill Monitoring (MONITA) software can be taken into consideration by PT XYZ in solving problems for developing software.
\end{abstract}

Keywords: Cost Estimation, Function Point Method, and PT XYZ.

\section{PENDAHULUAN}

Teknologi Informasi dan Komunikasi pada saat ini sudah berkembang pesat di seluruh bidang kegiatan. Perkembangan tersebut memicu banyaknya perangkat lunak yang muncul sesuai kebutuhan bidang kegiatan, salah satunya perusahaan. Perangkat lunak sangat membantu perusahaan dalam mendukung proses bisnisnya. PT XYZ merupakan salah satu perusahaan yang sudah menerapkan perangkat lunak untuk mendukung proses bisninya, seperti : Monitoring Tagihan (MONITA). Dalam mengestimasi biaya perangkat lunak permasalah yang biasa timbul yaitu : Over-Estimates dan UnderEstimates. Over-Estimates berdampak pada alokasi sumber daya lebih besar dari yang dibutuhkan, sedangkan UnderEstimates berdampak pada kualitas dari perangkat lunak yang dihasilkan tidak sesuai standar. Oleh karena itu, tingkat akurasi estimasi biaya sangat diperlukan agar tepat waktu, sesuai biaya dan terpenuhinya standar kualitas produk perangkat lunak.

Dalam pengembangan perangkat lunak terdapat beberapa metode estimasi biaya yang biasa digunakan, yaitu :

1. Metode Function Points yang pertamakali dikembangkan oleh A.J. Albrect pada tahun 1983 dan resmi dinyatakan oleh International Function Points User Group (IFPUG) [1]

2. Metode Cost Constructive Model (COCOMO) yang telah dikembangkan oleh B. Boehm.

3. Metode Use Case Point (UCP) yang dikembangakan oleh Karner pada tahun 1993.

Menurut Renny [2], metode FP dapat digunakan sebagai metode estimasi usaha yang cukup baik. Beberapa penelitian sebelumnya telah merekomendasikan metode FP apabila jangka waktu perencanaan proyek terbatas [3], [4]. Oleh karena itu, dalam estimasi biaya perangkat lunak Monitoring tagihan ini menggunakan metode Function Points.

\section{METODE PENELITIAN}

Allan J. Albrect merupakan pengembang metode Function Points Analysis sejak tahun 1983 di perusahaan IBM [1]. Metode Function Point adalah metode dengan pendekatan yang berorientasi pada fungsionalitas dan kompleksitas dalam memperkirakan ukuran perangkat lunak dan selanjutnya memperkirakan upaya dan estimasi biaya untuk pengembangan perangkat lunak [5]. Berikut tahapan-tahapan untuk melakukan estimasi biaya dengan menggunakan metode Function Points Analysis :

a. Menghitung Unadjusted Function Points (UFP) 
Dalam metode Function Points tersusun dari paramater utama yang memiliki bobot masing-masing Tabel 1. Menurut penelitian Albrect [1] ada lima parameter utama yaitu EI, EO, EQ, ILF dan ELF. Dalam menghitung UFP setiap nilai dikalikan dengan faktor kali kompleksitas masing-masing Tabel 2.

Tabel 1. Parameter Menghitung Unadjusted Function Points

\begin{tabular}{|c|c|}
\hline Parameter Utama & Deskripsi \\
\hline $\begin{array}{l}\text { External Input } \\
\quad \text { (EI) }\end{array}$ & $\begin{array}{l}\text { Proses dasar yang mengolah data atau mengontrol informasi yang datang dari luar } \\
\text { sistem }\end{array}$ \\
\hline $\begin{array}{l}\text { External Output } \\
\quad(\text { EO) }\end{array}$ & $\begin{array}{l}\text { Sebuah proses yang mengirimkan data atau informasi yang diproses terlebih dahulu } \\
\text { melalui process logic atau proses matematik. }\end{array}$ \\
\hline $\begin{array}{l}\text { External Inquiry } \\
\qquad(\mathrm{EQ})\end{array}$ & $\begin{array}{l}\text { girimkan data atau informasi keluar dari batas suatu sistem } \\
\text { a dilayar user). }\end{array}$ \\
\hline $\begin{array}{l}\text { Internal Logical } \\
\text { File (ILF) }\end{array}$ & $\begin{array}{l}\text { Kumpulan data atau informasi yang digunakan dalam aplikasi. Peran ILF adalah proses } \\
\text { menyimpan data dalam aplikasi (Database) }\end{array}$ \\
\hline $\begin{array}{l}\text { External Logical } \\
\text { File (ELF) }\end{array}$ & $\begin{array}{l}\text { Berkas yang dilewatkan atau dibagikan diantara system perangkat lunak yang dihitung } \\
\text { sebagai tipe berkas antarmuka eksternal dalam setiap sistem. (Referensi) }\end{array}$ \\
\hline
\end{tabular}

Tabel 2. Level Kompleksitas

\begin{tabular}{|c|c|c|c|c|c|c|c|c|c|c|}
\hline \multirow{3}{*}{$\begin{array}{c}\text { Tipe } \\
\text { Komponen }\end{array}$} & \multicolumn{9}{|c|}{ Level Kompleksitas } & \multirow{3}{*}{ Total } \\
\hline & \multicolumn{3}{|c|}{ Mudah } & \multicolumn{3}{|c|}{ Sedang } & \multicolumn{3}{|c|}{ Komplek } & \\
\hline & $\mathrm{J}$ & $\mathrm{B}$ & $\mathrm{P}$ & $\mathrm{J}$ & $\mathrm{B}$ & $\mathrm{P}$ & $\mathbf{J}$ & $\mathrm{B}$ & $\mathrm{P}$ & \\
\hline EI & - & 3 & - & - & 4 & - & - & 6 & - & - \\
\hline EO & - & 4 & - & - & 5 & - & - & 7 & - & - \\
\hline EQ & - & 3 & - & - & 4 & - & - & 6 & - & - \\
\hline ILF & - & 7 & - & - & 10 & - & - & 15 & - & - \\
\hline ELF & - & 5 & - & - & 7 & - & - & 10 & - & - \\
\hline \multicolumn{10}{|c|}{ Total UFP } & - \\
\hline
\end{tabular}

Keterangan :

J : Jumlah

B : Bobot

$\mathrm{P}:$ Poin

b. Menghitung Relative Complexity Adjustment Factor (RCAF)

Dalam menghitung RCAF digunakan 14 karakteristik RCAF untuk menghitung bobot kompleksitas perangkat lunak. Total RCAF merupakan total skor karakteristik. Karakteristik dibawah ini merupakan ketetapan atau konstanta yang dibuat oleh International Function Point Users Group (IFPUG).

Tabel 3. Bobot Relative Complexity Adjustment Factor

\begin{tabular}{cc}
\hline Skor & Keterangan \\
\hline 1 & Tidak pengaruh \\
2 & Insidial \\
3 & Moderat \\
4 & Rata-rata \\
5 & Essential \\
\hline
\end{tabular}

Tabel 4. Bobot Karakteristik Relative Complexity Adjustment Factor

\begin{tabular}{clccccc}
\hline \multicolumn{1}{c}{ Karakteristik } & \multicolumn{5}{c}{ Skor } \\
No & & $\mathbf{1}$ & $\mathbf{2}$ & $\mathbf{3}$ & $\mathbf{4}$ & $\mathbf{5}$ \\
\hline 1 & Tingkat kehandalan dan pemulihan data & $\mathrm{O}$ & $\mathrm{O}$ & $\mathrm{O}$ & $\mathrm{O}$ & $\mathrm{O}$ \\
2 & Tingkat komunikasi data & $\mathrm{O}$ & $\mathrm{O}$ & $\mathrm{O}$ & $\mathrm{O}$ & $\mathrm{O}$ \\
3 & Tingkat distribusi pemrosesan data & $\mathrm{O}$ & $\mathrm{O}$ & $\mathrm{O}$ & $\mathrm{O}$ & $\mathrm{O}$ \\
4 & Tingkat capaian kerja & $\mathrm{O}$ & $\mathrm{O}$ & $\mathrm{O}$ & $\mathrm{O}$ & $\mathrm{O}$ \\
5 & Tingkat konfigurasi lingkungan & $\mathrm{O}$ & $\mathrm{O}$ & $\mathrm{O}$ & $\mathrm{O}$ & $\mathrm{O}$ \\
6 & Tingkat kapasitas transaksi & $\mathrm{O}$ & $\mathrm{O}$ & $\mathrm{O}$ & $\mathrm{O}$ & $\mathrm{O}$ \\
7 & Tingkat efisiensi pengguna & $\mathrm{O}$ & $\mathrm{O}$ & $\mathrm{O}$ & $\mathrm{O}$ & $\mathrm{O}$ \\
8 & Tingkat pembaruan file induk & $\mathrm{O}$ & $\mathrm{O}$ & $\mathrm{O}$ & $\mathrm{O}$ & $\mathrm{O}$ \\
9 & Tingkat pembaruan real time online & $\mathrm{O}$ & $\mathrm{O}$ & $\mathrm{O}$ & $\mathrm{O}$ & $\mathrm{O}$ \\
10 & Tingkat penggunaan kembali & $\mathrm{O}$ & $\mathrm{O}$ & $\mathrm{O}$ & $\mathrm{O}$ & $\mathrm{O}$ \\
11 & Tingkat kemudahan instalasi & $\mathrm{O}$ & $\mathrm{O}$ & $\mathrm{O}$ & $\mathrm{O}$ & $\mathrm{O}$ \\
12 & Tingkat kemudahan penggunaan & $\mathrm{O}$ & $\mathrm{O}$ & $\mathrm{O}$ & $\mathrm{O}$ & $\mathrm{O}$ \\
\hline
\end{tabular}


c. Menghitung Function Points (FP)

Berikut rumus menghitung Function Points (FP) :

$$
\mathrm{FP}=\mathrm{UFP} \times(0,65+(0,01 \times \mathrm{RCAF}))
$$

Keterangan :

0,65 dan $0,01=$ Nilai konstan yang dibuat oleh IFPUG

d. Menghitung Effort

Dalam menghitung effort terdapat nilai FP yang telah diketahui dan pembangunan berdasarkan waktu (Man/Hours).

Dalam function point ini untuk Productivity Factor yang bernilai 8.2 [6]

$$
\text { Effort }=\text { FP } \times \text { PF }
$$

e. Menghitung Source Lines of Code (SLoC)

Nilai 56 merupakan nilai dari ketetapan atau konstanta dengan indeks bahasa pemograman PHP dalam yang merupakan

Productivity Factor dari bahasa pemograman HTML/Javascript

$$
\mathrm{SloC}=\mathrm{FP} \times 56
$$

f. Menghitung Estimasi Effort

Nilai estimasi effort ini digunakan untuk pembangunan berdasarkan Man/Hour

$$
\frac{\text { Effort }}{18} \times \sum h k \times j k
$$

g. Menghitung Pendistribusian Effort ke Aktivitas

Setiap effort yang telah diketahui di distribusikan ke dalam setiap aktivitas yang bertujuan untuk mencari estimasi biaya yang dibutuhkan dalam membangun perangkat lunak.

Persentase x SLoC ke Effort

Untuk menghitung Cost ke dalam setiap aktivitas menggunakan rumus sebagai berikut :

Effort * EffortPayrate/hr

Tabel 5. Persentase Aktivitas

\begin{tabular}{clc}
\hline No & \multicolumn{1}{c}{ Aktivitas } & Persentase (\%) \\
\hline 1 & Requirements & 1,6 \\
2 & Specifications & 7,5 \\
3 & Design & 6 \\
4 & Implementation & 52 \\
5 & Integration Testing & 7 \\
6 & Acceptance \& deployment & 5,5 \\
7 & Project Management & 3,8 \\
8 & Configuration Management & 4,3 \\
9 & Quality Assurance & 0,9 \\
10 & Documentation & 8,4 \\
11 & Training \& Support & 1 \\
12 & Evaluation \& Testing & 2 \\
\multicolumn{2}{c}{ Total } & 100 \\
\hline
\end{tabular}

\section{ANALISA DAN PEMBAHASAN}

Untuk mengetahui nilai estimasi biaya pengembangan perangkat lunak MONITA maka perlu dilakukan perhitungan. Berikut tahap-tahap menghitung estimasi biaya dengan mmenggunakan metode Function Point seperti berikut ini :

a. Unadjusted Function Points (UFP)

Tabel 6. Unadjusted Function Points MONITA

\begin{tabular}{cccc}
\hline Tipe & \multicolumn{3}{c}{ Level Kompleksitas } \\
\cline { 2 - 4 } Komponen & Mudah & Sedang & Total \\
\hline
\end{tabular}




\begin{tabular}{|c|c|c|c|c|c|c|c|c|c|c|}
\hline & $\mathbf{J}$ & B & $\mathrm{P}$ & $\mathrm{J}$ & B & $\mathrm{P}$ & $\mathbf{J}$ & B & $\mathrm{P}$ & \\
\hline EI & 10 & 3 & 30 & 4 & 4 & 16 & 4 & 6 & 24 & 70 \\
\hline EO & 10 & 4 & 40 & 4 & 5 & 20 & 4 & 7 & 0 & 60 \\
\hline EQ & 1 & 3 & 3 & 0 & 4 & 0 & 0 & 6 & 0 & 3 \\
\hline ILF & 4 & 7 & 0 & 3 & 10 & 30 & 0 & 15 & 0 & 30 \\
\hline ELF & 3 & 5 & 15 & 0 & 7 & 0 & 0 & 10 & 0 & 15 \\
\hline \multicolumn{10}{|c|}{ Total UFP } & 178 \\
\hline
\end{tabular}

b. Relative Complexity Adjustment Factor (RCAF)

Tabel 7. Relative Complexity Adjustment Factor

\begin{tabular}{|c|c|c|c|c|c|c|}
\hline \multirow{2}{*}{ No } & \multirow{2}{*}{ Karakteristik } & \multicolumn{5}{|c|}{ Skor } \\
\hline & & 1 & 2 & 3 & 4 & 5 \\
\hline 1 & Tingkat kehandalan dan pemulihan data & $\mathrm{O}$ & $\mathrm{O}$ & $\mathrm{O}$ & $\mathrm{O}$ & $\mathrm{O}$ \\
\hline 2 & Tingkat komunikasi data & $\mathrm{O}$ & $\mathrm{O}$ & $\mathrm{O}$ & $\mathrm{O}$ & $\mathrm{O}$ \\
\hline 3 & Tingkat distribusi pemrosesan data & $\mathrm{O}$ & $\mathrm{O}$ & $\mathrm{O}$ & $\mathrm{O}$ & $\mathrm{O}$ \\
\hline 4 & Tingkat capaian kerja & $\mathrm{O}$ & $\mathrm{O}$ & $\mathrm{O}$ & $\mathrm{O}$ & $\mathrm{O}$ \\
\hline 5 & Tingkat konfigurasi lingkungan & $\mathrm{O}$ & $\mathrm{O}$ & $\mathrm{O}$ & $\mathrm{O}$ & $\mathrm{O}$ \\
\hline 6 & Tingkat kapasitas transaksi & $\mathrm{O}$ & $\mathrm{O}$ & $\mathrm{O}$ & $\mathrm{O}$ & $\mathrm{O}$ \\
\hline 7 & Tingkat efisiensi pengguna & $\mathrm{O}$ & $\mathrm{O}$ & $\mathrm{O}$ & $\mathrm{O}$ & $\mathrm{O}$ \\
\hline 8 & Tingkat pembaruan file induk & $\mathrm{O}$ & $\mathrm{O}$ & $\mathrm{O}$ & $\mathrm{O}$ & $\mathrm{O}$ \\
\hline 9 & Tingkat pembaruan real time online & $\mathrm{O}$ & $\mathrm{O}$ & $\mathrm{O}$ & $\mathrm{O}$ & $\mathrm{O}$ \\
\hline 10 & Tingkat penggunaan kembali & $\mathrm{O}$ & $\mathrm{O}$ & $\mathrm{O}$ & $\mathrm{O}$ & $\mathrm{O}$ \\
\hline 11 & Tingkat kemudahan instalasi & $\mathrm{O}$ & $\mathrm{O}$ & $\mathrm{O}$ & $\mathrm{O}$ & $\mathrm{O}$ \\
\hline 12 & Tingkat kemudahan penggunaan & $\mathrm{O}$ & $\mathrm{O}$ & $\mathrm{O}$ & $\mathrm{O}$ & $\mathrm{O}$ \\
\hline 13 & Tingkat variasi organisasi pengguna & $\mathrm{O}$ & $\mathrm{O}$ & $\mathrm{O}$ & $\mathrm{O}$ & $\mathrm{O}$ \\
\hline 14 & Tingkat kerentanan terhadap perubahan & $\mathrm{O}$ & $\mathrm{O}$ & $\mathrm{O}$ & $\mathrm{O}$ & $\mathrm{O}$ \\
\hline & Total RCAF & & & 38 & & \\
\hline
\end{tabular}

c. Menghitung Function Points (FP)

$$
\begin{aligned}
\mathrm{FP} & =\operatorname{UFP} \times(0,65+(0,01 \times \mathrm{RCAF})) \\
& =178 \times(0,65+0,01 \times 38)) \\
& =183,34
\end{aligned}
$$

d. Menghitung Effort

$$
\begin{aligned}
\text { Effort } & =\mathrm{FP} \times \mathrm{PF} \\
& =183,34 \times 8,2 \\
& =1503,39
\end{aligned}
$$

e. Menghitung Source Lines of Code (SloC)

\begin{tabular}{|c|c|c|c|c|c|}
\hline No & Aktivitas & $\begin{array}{c}\text { Persentase } \\
(\%)\end{array}$ & $\begin{array}{c}\text { Effort }= \\
\text { SLoC x \% }\end{array}$ & $\begin{array}{l}\text { Payrate/hr } \\
\text { (IDR) }\end{array}$ & $\begin{array}{c}\text { Cost }=\text { effort } x \\
\text { payrate } \\
\text { (IDR) }\end{array}$ \\
\hline 1 & Requirements & 1.6 & 28,68 & 39.773 & 1.140 .782 \\
\hline 2 & Specifications & 7.5 & 134,45 & 39.773 & 5.347 .416 \\
\hline 3 & Design & 6 & 107,56 & 45.455 & 4.889 .066 \\
\hline 4 & Implementation & 52 & 932,18 & 45.455 & 42.371 .906 \\
\hline 5 & $\begin{array}{l}\text { Integration } \\
\text { Testing }\end{array}$ & 7 & 125,49 & 45.455 & 5.703 .910 \\
\hline 6 & $\begin{array}{l}\text { Acceptance \& } \\
\text { deployment }\end{array}$ & 5.5 & 98,60 & 45.455 & 4.481 .644 \\
\hline
\end{tabular}

$$
\begin{aligned}
\text { SloC } & =\text { FP } \times 56 \\
& ==183,34 \times 56 \\
& =10.267,04
\end{aligned}
$$

f. Menghitung Estimasi Effort

$$
\begin{aligned}
\text { Estimasi Effort } & =\frac{\text { Effort }}{18} \times 22 \text { hari kerja } \times 8 \text { jam kerja } \\
& =\frac{1.503,39}{18} \times 22 \text { hari } \text { kerja } \times 8 \text { jam kerja } \\
& =1.792,66
\end{aligned}
$$

g. Menghitung Pendistribusian Effort ke Aktivitas

Tabel 8. Distribusi Effort ke Aktivitas MONITA 


\begin{tabular}{|c|c|c|c|c|c|}
\hline 7 & $\begin{array}{l}\text { Project } \\
\text { Management }\end{array}$ & 3.8 & 68,12 & 113.636 & 7.741 .022 \\
\hline 8 & $\begin{array}{l}\text { Configuration } \\
\text { Management }\end{array}$ & 4.3 & 77,08 & 113.636 & 8.759 .577 \\
\hline 9 & $\begin{array}{l}\text { Quality } \\
\text { Assurance }\end{array}$ & 0.9 & 16,13 & 45.455 & 733.360 \\
\hline 10 & Documentation & 8.4 & 150,58 & 45.455 & 6.844 .693 \\
\hline 11 & $\begin{array}{l}\text { Training \& } \\
\text { Support }\end{array}$ & 1 & 17,93 & 45.455 & 814.844 \\
\hline 12 & $\begin{array}{l}\text { Evaluation \& } \\
\text { Testing }\end{array}$ & 2 & 35,85 & 45.455 & 1.629 .689 \\
\hline & Total & 100 & $1.792,66$ & & 90.457 .909 \\
\hline
\end{tabular}

\section{KESIMPULAN}

Dari penelitian yang telah dilakukan, estimasi biaya pengembangan perangkat lunak MONITA PT XYZ, maka disimpulkan apabila bahwa PT XYZ ingin mengembangkan perangkat lunak MONITA maka dibutuhkan kurang lebih sebesar IDR 90.457.909 atau setara dengan effort 1.792,66 orang/jam. Penulis mengabaikan faktor-faktor eksternal terutama kesiapan insfrakstruktur dakam mengimplementasikan MONITA. Oleh karena itu, perhitungan estimasi effort dan biaya juga disesuaikan dengan kondisi pemilik perangkat lunak

\section{REFERENCES}

[1] A. J. Albrecht and J. E. Gaffney, "Software Function, Source Lines of Code, and Development Effort Prediction: A Software Science Validation," IEEE Trans. Softw. Eng., 1983.

[2] R. S. Dewi, "Implementasi Metode Function Points Untuk Mengestimasi Usaha Pada Proyek Pembangunan Aplikasi Layanan Publik," J. Sist. Inf. Indones., vol. 2, no. 1, pp. 1-8, 2017

[3] R. S. Dewi, A. P. Subriadi, and Sholiq, "A Modification Complexity Factor in Function Points Method for Software Cost Estimation Towards Public Service Application," in Procedia Computer Science, 2017.

[4] R. S. Dewi, T. W. Andari, M. B. A. Rasyid, and R. Candra A.P., "Ekstraksi Faktor Kompleksitas Game Menggunakan Metode Function Points," J. Teknol. dan Sist. Inf., 2018.

[5] A. Yhurinda, P. Putri, and A. P. Subriadi, "Software Cost Estimation Using Function Point Analysis," IPTEK J. Proc. Ser., vol. 0, no. 1, pp. 79-83, 2019.

[6] P. L. Primandaria and Sholiq, "Effort Distribution to Estimate Cost in Small to Medium Software Development Project with Use Case Points," in Procedia Computer Science, 2015. 